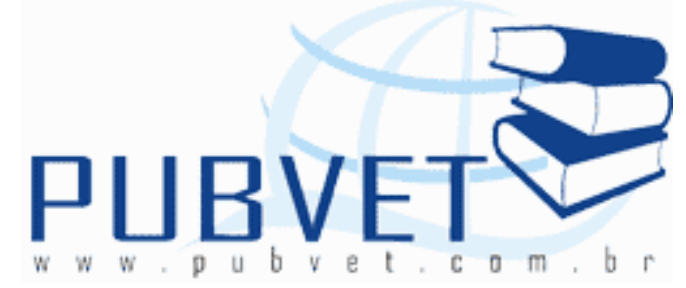

PUBVET, Publicações em Medicina Veterinária e Zootecnia.

\title{
Avaliação físico-química de leite in natura comercializado informalmente nas cidades de Cerqueira César, Manduri e Avaré/SP.
}

Sofia Dalaqua ${ }^{1}$, Gessler Gomes Nogueira ${ }^{1}$, Ulisses Aparecido do Nascimento ${ }^{1}$,

Thiago Augusto Laurano ${ }^{1}$, Letícia Borges de Sousa Nunes² ${ }^{2}$ Fábio Sossai Possebon ${ }^{2}$, Thiago Luiz Belém Spina ${ }^{2}$, Caio Vacilloto Zuim² ${ }^{2}$, Germano Francisco Biondi $^{2}$, Otávio Augusto Martins ${ }^{1,2}$

${ }^{1}$ Faculdades Integradas Regionais de Avaré, Fundação Regional Educacional de Avaré, São Paulo, Brasil.

2 Faculdade de Medicina Veterinária e Zootecnia, Universidade Estadual Paulista "Júlio de Mesquita Filho" (UNESP), Campus de Botucatu, São Paulo, Brasil.

\section{Resumo}

Apesar de ser proibida pela legislação, a comercialização de leite cru sem fiscalização é uma prática comum em muitas cidades no Brasil. O objetivo deste trabalho foi avaliar os parâmetros físico-químicos deste produto comercializados em três municípios do estado de São Paulo. Foram analisadas amostras obtidas a partir de comerciantes ambulantes informais e encaminhadas para o Laboratório de Química e Bioquímica das Faculdades Integradas Regionais de Avaré - Fundação Regional Educacional de Avaré. Foram analisadas a acidez, densidade, gordura, sólidos totais (ST), sólidos não gordurosos (SNG), índice de crioscopia, pesquisa de fosfatase, peroxidase, 
formol, água oxigenada $\left(\mathrm{H}_{2} \mathrm{O}_{2}\right)$, hipoclorito $\left(\mathrm{ClO}^{-}\right)$e cloreto $\left(\mathrm{Cl}^{-}\right)$. Os principais resultados demonstraram que não existem diferenças significativas $(p>0,05)$ nos teores de acidez nas cidades de Cerqueira César, Manduri e Avaré. Entretanto, os teores de densidade, gordura, ST, SNG e índice de crioscopia na cidade de Avaré apresentaram diferença significativa $(p<0,05)$ comparadas com as demais cidades. As porcentagens das ausências da enzima fosfatase no leite in natura foram de $26,67 \%$ na cidade de Cerqueira César e da enzima peroxidase foi de $13,33 \%$ na cidade de Manduri. As substâncias orgânica (formaldeído) e inorgânicas $\left(\mathrm{H}_{2} \mathrm{O}_{2}, \mathrm{ClO}^{-}\right.$e $\left.\mathrm{Cl}^{-}\right)$estavam ausentes nos leites in natura comercializados nas cidades de Cerqueira César, Manduri e Avaré. A principal conclusão consiste em afirmar que a qualidade físico-química de leite in natura não inspecionado e comercializado por inúmeros comerciantes ambulantes das cidades de Cerqueira César, Manduri e Avaré no estado de São Paulo não é satisfatória e legal.

Palavras-chave: Leite in natura; Qualidade; Físico-Química.

\title{
Physical-chemical evaluation of in natura milk marketed informally in the cities of Cerqueira César, Manduri and Avaré - São Paulo
}

\begin{abstract}
Although forbidden by law, raw milk sales without sanitary supervision are a usual practice in many Brazilian cities. The aim of this study was evaluate the physical-chemical parameters of this product commercialized in three cities from São Paulo state. Were analyzed samples obtained from informal street merchants and sent to the Laboratory of Chemistry and Biochemistry, of Faculdades Integradas Regionais de Avaré - Fundação Regional Educacional de Avaré. Were analyzed the acidity, density, fat, total solids (TS), solids-not-fat (SNF), freezing point, phosphatase and peroxidase presence, formaldehyde, hydrogen peroxide $\left(\mathrm{H}_{2} \mathrm{O}_{2}\right)$, hypochlorite $\left(\mathrm{ClO}^{-}\right)$and chloride $\left(\mathrm{Cl}^{-}\right)$. The main results showed no significant differences $(p>0.05)$ in acidity levels in the cities of Cerqueira César, Manduri and Avaré. The rates of phosphatase enzyme
\end{abstract}


absences were $26.67 \%$ in Cerqueira César and for the peroxidase enzyme absences, $13.33 \%$ in Manduri. The organic substances (formaldehyde) and inorganic $\left(\mathrm{H}_{2} \mathrm{O}_{2}, \mathrm{Cl}^{-}\right.$and $\left.\mathrm{ClO}^{-}\right)$were absent in the raw milk sold in Cerqueira Cesar, Manduri and Avaré. It is concluded that the physical-chemical quality of not inspected raw milk sold by several traders from the cities of Cerqueira César, Manduri and Avaré in the state of Sao Paulo is not satisfactory and legal.

Keywords: Raw Milk, Quality, Physical-Chemical

\section{Introdução}

O Brasil é o sexto maior produtor de leite do mundo, sendo responsável por $66 \%$ do volume total produzido nos países que compõem o Mercosul. 0 leite destaca-se pela sua característica nutritiva, sendo rico em nutrientes essenciais ao crescimento e à manutenção de uma vida saudável (BRASIL, 2012).

Legalmente, o leite é definido como produto oriundo da ordenha completa e ininterrupta, em condições de higiene, de vacas sadias, bem alimentadas e descansadas (BRASIL, 1998). Sua composição é normalmente representada por proteínas $(3 \%)$, gorduras $(3,6 \%)$, lactose $(4,5 \%)$, e sais $(0,7 \%)$. A água é um dos principais componentes, correspondendo a $87,5 \%$ do seu volume e influindo sensivelmente na densidade; o restante, $12,5 \%$ de matéria seca total, compreende matéria gorda, caseína, albumina e lactose. A composição pode variar de acordo com a espécie, a raça, a individualidade, a alimentação, o tempo de gestação e outros fatores (PEREDA, 2005).

Do ponto de vista biológico, o leite é o produto da secreção das glândulas mamárias de fêmeas, cuja função natural é a alimentação dos recém-nascidos. Do ponto de vista físico-químico, o leite é uma mistura homogênea de grande número de substâncias (lactose, glicerídeos, proteínas, sais, vitaminas, enzimas, etc.), das quais algumas estão em emulsão (a gordura e as substâncias associadas), algumas em suspensão (as caseínas ligadas a sais 
minerais) e outras em dissolução verdadeira (lactose, vitaminas hidrossolúveis, proteínas do soro, sais, etc.) (PEREDA, 2005).

Ao ser sintetizado e secretado nos alvéolos da glândula mamaria, o leite é estéril, mas os processos que envolvem sua obtenção podem levar a contaminação por microrganismos originários do interior da glândula mamaria e de várias fontes externas relacionadas ao ambiente, utensílios, equipamentos etc. Esta contaminação pode incluir tanto microrganismos patogênicos como deterioradores. A contaminação microbiana prejudica a qualidade do leite, interfere na industrialização, reduz o tempo de prateleira do leite fluido e derivado lácteos e pode colocar em risco a saúde do consumidor (BRITO, 2000).

O leite cru, não pasteurizado, pode carrear diversos microrganismos responsáveis por causar numerosas doenças veiculadas por alimentos. Estes agentes podem afetar seriamente a saúde de do consumidor (ABRAHÃO, 2005).

De açodo com a legislação é proibida a venda de leite cru para consumo direto da população, em todo o território nacional, nos termos do Decreto-lei no 923, de 10 de outubro de 1969 (BRASIL, 1969).

Apesar dessa proibição legal a venda deste tipo de leite tem sido realizada abertamente em numerosas cidades do Estado, muitas delas possuidoras de elevado nível socioeconômico e cultural (QUEIROZ, 1995).

De acordo com a Organização Mundial da Saúde (OMS), existem 7 doenças viróticas básicas e 16 doenças bacterianas veiculadas pelo leite, destacando-se: ricketisioses (febreQ), infecções e intoxicações bacterianas (tuberculose, brucelose, listeriose, clostridioses), intoxicações alimentares (principalmente devido à toxina do Staphylococcus aureus), febres tifóide e paratifóide, salmonelose e intoxicações estreptocócicas. Verificou-se ainda, que o leite também pode veicular inseticidas, desinfetantes, metais pesados, toxinas e drogas diversas (BRANDÃO, 1994; BADINI et al., 1996; OLIVAL \& SPEXOTO, 2004). 
Com base nessas informações, o presente trabalho tem por objetivo avaliar a qualidade físico-química de leite in natura não inspecionado e comercializado por inúmeros comerciantes ambulantes das cidades de Cerqueira César, Manduri e Avaré no estado de São Paulo.

\section{Materiais e Métodos}

\section{Amostras}

Foram adquiridas 45 amostras de leite in natura de comerciantes ambulantes informais nas cidades de Avaré, Cerqueira César e Manduri - São Paulo. As amostras foram acondicionadas em recipientes isotérmicos com gelo reciclável e encaminhadas para as análises no Laboratório de Química e Bioquímica das Faculdades Integradas Regionais de Avaré - Fundação Regional Educacional de Avaré.

Determinação quantitativa da acidez $\left({ }^{\circ} D\right)$

Foram transferidos $10 \mathrm{~mL}$ da amostra com o auxílio de uma pipeta volumétrica para um béquer de $100 \mathrm{~mL}$. Foram adicionadas 5 gotas de solução alcoólica de fenolftaleína a $1 \%$ e titulou-se com solução de hidróxido de sódio a N/9, até evidenciar o ponto de viragem indicado pela cor rósea. Cada 0,1 mL da solução de hidróxido de sódio a N/9 corresponde a $1^{\circ} \mathrm{D}$.

\section{Determinação da densidade $\left(\mathrm{gmL}^{-1}\right)$}

Foram transferidos cerca de $200 \mathrm{~mL}$ de leite homogeneizado em uma proveta de $250 \mathrm{~mL}$. Foi introduzido o termolactodensímetro de Gerber ${ }^{\circledR}$. Após a estabilização do aparelho na proveta, foi feita a leitura ao nível do leite na coluna da densidade e da temperatura no termômetro. Os valores foram corrigidos à temperatura de $15^{\circ} \mathrm{C}$. 


\section{Determinação de gordura (Método de Gerber $^{\circledR}$ )}

Foram transferidos $10 \mathrm{~mL}$ de solução de ácido sulfúrico $(\mathrm{d}=1,820-1,825$ $\left.\mathrm{gmL}^{-1}\right), 11 \mathrm{~mL}$ de leite homogeneizado e $1 \mathrm{~mL}$ de solução de álcool isso-amílico $\left(\mathrm{d}=0,815 \mathrm{gmL}^{-1}\right)$ em um lactobutirômetro de Gerber ${ }^{\circledR}$. Homogeneizou-se e transferiu-se para o aparelho de centrifugação a 1200 rpm por 5 minutos. Em seguida, foi colocado no banho-maria a $65^{\circ} \mathrm{C}$ por 5 minutos. A leitura foi feita na escala do lactobutirômetro após ajuste da camada de gordura.

Determinação do índice crioscópico $\left({ }^{\circ} \mathrm{H}\right)$

Foi utilizado o crioscópio eletrônico de modelo MK 540, da marca ITR. Aproximadamente $2,5 \mathrm{~mL}$ da amostra foram adicionados ao frasco próprio do equipamento previamente calibrado, e após a análise era feita a leitura no mostrador digital.

Determinação dos sólidos totais (\% ST)

Foi utilizado o disco de Ackermann para determinação dos sólidos totais, confrontando os valores da densidade e da gordura em suas respectivas escalas e procedendo com a leitura na graduação externa.

\section{Determinação dos sólidos não gordurosos (\% SNG)}

A determinação dos sólidos não gordurosos foi realizada através de uma equação matemática, onde foi subtraído o valor da gordura dos sólidos totais segundo a seguinte fórmula: \%SNG = \%ST - \%G.

\section{Pesquisa de formol com floroglucina}

Foram pipetados $10 \mathrm{~mL}$ de leite homogeneizado em um tubo de ensaio e adicionou-se $1 \mathrm{~mL}$ de solução de floroglucina a $1 \%$. Após agitação, foram adicionados $2 \mathrm{~mL}$ de solução de hidróxido de sódio a 10\%. Interpretação: amostras positivas - coloração salmão avermelhada; e amostras negativas sem alteração de cor. 
Pesquisa de água oxigenada $\left(\mathrm{H}_{2} \mathrm{O}_{2}\right)$ pela técnica do guaiacol

Transferiu-se $10 \mathrm{~mL}$ da amostra homogeneizada para um tubo de ensaio e foi adicionado $2 \mathrm{~mL}$ de solução de guaiacol a $1 \%$. Em casos da existência de $\mathrm{H}_{2} \mathrm{O}_{2}$ se observaria o desprendimento de oxigênio.

\section{Pesquisa de hipoclorito $\left(\mathrm{ClO}^{-}\right)$}

Foram transferidos $10 \mathrm{~mL}$ da amostra homogeneizada para o tubo de ensaio, adicionou-se $1,5 \mathrm{~mL}$ de solução de iodeto de potássio a $10 \%$ e 4 gotas de solução de ácido clorídrico 1+1. Interpretação: Amostra positiva - coloração do amarelo para o marrom.

\section{Pesquisa da fosfatase alcalina}

Foi utilizado o método colorimétrico da fosfatase alcalina (Labtest ${ }^{\circledR}$ ) e o procedimento metodológico foi de acordo com a orientação do fabricante.

\section{Pesquisa da peroxidase}

Foram transferidas $10 \mathrm{~mL}$ de leite homogeneizado para tubo de ensaio e aquecidas em banho-maria a $43^{\circ} \mathrm{C}$ por 5 minutos. Foram adicionados $2 \mathrm{~mL}$ de solução de guaiacol a $1 \%$ e 3 gotas de solução de água oxigenada de 10 volumes. Interpretação: coloração salmão foi considerada positiva.

\section{Determinação de cloretos $\left(\mathrm{Cl}^{-}\right)$}

Foram transferidos para um tubo de ensaio $10 \mathrm{~mL}$ de leite, e foram adicionados $4,5 \mathrm{~mL}$ de solução de nitrato de prata a $0,1 \mathrm{~N}$ e 10 gotas de solução de cromato de potássio a 10\%. A amostra que revelou coloração amarela foi considerada positiva e as amostras com coloração marrom alaranjado foram consideradas negativas (BRASIL, 1985).

\section{Análise estatística}

O estudo estatístico das variáveis foi realizado através da ANOVA e complementado com o teste de comparações múltiplas de Tukey para 
contraste entre médias dos tratamentos. Os resultados foram expressos em média \pm erro padrão da média. As conclusões estatísticas foram realizadas com $5 \%$ de significância.

\section{Resultados}

O valor médio do teor de acidez do leite in natura da cidade de Avaré apresentou uma diferença significativa $(p<0,05)$ comparada com o leite das demais cidades. As porcentagens dos teores de acidez abaixo de $14^{\circ} \mathrm{D}$ foram de $13,33 \%, 6,67 \%$ e $6,67 \%$ nas respectivas cidades de Cerqueira César, Manduri e Avaré. No entanto, as porcentagens dos teores de acidez acima de $18^{\circ} \mathrm{D}$ foram de $26,67 \%, 40 \%$ e $60 \%$ nas respectivas cidades de Cerqueira César, Manduri e Avaré (Tabela 01).

$\mathrm{Na}$ cidade de Avaré, a média da densidade apresentou uma diferença significativa $(p<0,05)$ comparada com o leite das demais cidades. As porcentagens das densidades menores que 1,028 g. $\mathrm{mL}^{-}$foram de 6,67\%, $6,67 \%$ e $0,00 \%$ nas respectivas cidades de Cerqueira César, Manduri e Avaré. As porcentagens das densidades maiores que $1,034 \mathrm{~g} \cdot \mathrm{mL}^{-}$foram de $0,00 \%$, 0,00\% e 66,67\% nas respectivas cidades de Cerqueira César, Manduri e Avaré (Tabela 02).

$\mathrm{Na}$ Tabela 03 demonstra que o valor médio do teor gordura do leite in natura da cidade de Avaré tem uma diferença significativa $(p<0,05)$ comparada com o leite das demais cidades. As porcentagens dos teores de gordura inferior a $3 \%$ foram de $20,00 \%, 13,33 \%$ e $0,00 \%$ nas respectivas cidades de Cerqueira César, Manduri e Avaré.

Nas Tabelas 04 e 05 demonstram que os valores médios de sólidos totais e de sólidos não gordurosos do leite in natura da cidade de Avaré tem uma diferença significativa $(p<0,05)$ comparada com o leite das demais cidades. As porcentagens dos valores de sólidos não gordurosos menores que $8,40 \%$ foram de $86,67 \%, 53,33 \%$ e $0,00 \%$ nas respectivas cidades de Cerqueira César, Manduri e Avaré. 
O índice de crioscopia apresentou uma diferença significativa $(p<0,05)$ na cidade de Avaré comparada com as demais cidades. As porcentagens dos índices de crioscopia superiores a $-0,530^{\circ} \mathrm{H}$ foram de 20,00\%, 26,67\% e $6,67 \%$ nas respectivas cidades de Cerqueira César, Manduri e Avaré. No entanto, as porcentagens dos índices de crioscopia inferiores a $-0,550^{\circ} \mathrm{H}$ foram de $33,33 \%$, 20,00\% e 73,33\% nas respectivas cidades de Cerqueira César, Manduri e Avaré (Tabela 06).

As porcentagens da ausência da enzima fosfatase no leite in natura foram de 26,67\%, 13,33\% e 0,00\% nas respectivas cidades de Cerqueira César, Manduri e Avaré. Na análise qualitativa da pesquisa da enzima peroxidase, a porcentagem de ausência foi de $13,33 \%$ no leite in natura comercializado na cidade de Manduri. As substâncias orgânica (formaldeído) e inorgânicas $\left(\mathrm{H}_{2} \mathrm{O}_{2}, \mathrm{ClO}^{-} \mathrm{e} \mathrm{Cl}^{-}\right)$estavam ausentes nos leites in natura comercializados nas cidades de Cerqueira César, Manduri e Avaré (Tabela 07).

Tabela 01 - Média \pm erro padrão e porcentagem do valor de acidez quantitativo (Método Dornic) de leite in natura comercializado informalmente nos municípios de Cerqueira César, Manduri e Avaré no estado de São Paulo. Análise estatística complementada com o teste de Tukey $(p<0,05)$.

\begin{tabular}{|c|c|c|c|c|}
\hline \multirow[b]{2}{*}{ Cidade } & \multirow[b]{2}{*}{$\begin{array}{c}\text { Média } \pm \\
\text { erro padrão }\end{array}$} & \multicolumn{3}{|c|}{$\%$} \\
\hline & & $<14^{\circ} \mathrm{D}$ & $\begin{array}{c}14^{\circ} \mathrm{D}- \\
18^{\circ} \mathrm{D}\end{array}$ & $\stackrel{>}{18^{\circ} \mathrm{D}}$ \\
\hline $\begin{array}{c}\text { Cerqueira } \\
\text { César }\end{array}$ & $\begin{array}{c}15,51^{\circ} \mathrm{D} \pm \\
0,59 \mathrm{a}^{1}\end{array}$ & 13,33 & 60,00 & 26,67 \\
\hline Manduri & $\begin{array}{c}17,30^{\circ} \mathrm{D} \pm \\
1,03 \mathrm{a}\end{array}$ & 6,67 & 53,33 & 40,00 \\
\hline Avaré & $\begin{array}{c}18,20^{\circ} \mathrm{D} \pm \\
0,78 \mathrm{a}\end{array}$ & 6,67 & 33,33 & 60,00 \\
\hline
\end{tabular}

${ }^{1}$ Análise estatística e Teste de Tukey $(p=0,3520)$. 
Tabela 02 - Média \pm erro padrão e porcentagem do valor de densidade (g.mL) de leite in natura comercializado informalmente nos municípios de Cerqueira César, Manduri e Avaré no estado de São Paulo. Análise estatística complementada com o teste de Tukey $(p<0,05)$.

\begin{tabular}{ccccc}
\hline Cidade & $\begin{array}{c}\text { Média } \pm \\
\text { erro padrão }\end{array}$ & $\mathbf{< 1 , 0 2 8}$ & $\begin{array}{c}\mathbf{1 , 0 2 8}- \\
\mathbf{1 , 0 3 4}\end{array}$ & $\mathbf{> 1 , 0 3 4}$ \\
\hline $\begin{array}{c}\text { Cerqueira } \\
\text { César }\end{array}$ & $\begin{array}{l}1,0292 \pm \\
0,0004 \mathrm{a}^{1}\end{array}$ & 6,67 & 93,33 & 0,00 \\
Manduri & $\begin{array}{c}1,0301 \pm \\
0,0005 \mathrm{a}\end{array}$ & 6,67 & 93,33 & 0,00 \\
Avaré & $\begin{array}{l}1,0351 \pm \\
0,0007 \mathrm{~b}\end{array}$ & 0,00 & 33,33 & 66,67 \\
\hline${ }^{1}$ Análise estatística e Teste de Tukey $(p<0,0001)$.
\end{tabular}

${ }^{1}$ Análise estatística e Teste de Tukey $(p<0,0001)$.

Tabela 03 - Média \pm erro padrão e porcentagem do valor de gordura (\%) de leite in natura comercializado informalmente nos municípios de Cerqueira César, Manduri e Avaré no estado de São Paulo. Análise estatística complementada com o teste de Tukey $(p<0,05)$.

\begin{tabular}{cccc}
\hline \multirow{2}{*}{ Cidade } & Média \pm erro & \multicolumn{3}{c}{$\%$} \\
\cline { 3 - 4 } & padrão & $<\mathbf{3 \%}$ & $\mathbf{2 3 \%}$ \\
\hline Cerqueira César & $3,17 \pm 0,06 \mathrm{a}^{1}$ & 20,00 & 80,00 \\
Manduri & $3,21 \pm 0,07 \mathrm{a}$ & 13,33 & 86,67 \\
Avaré & $3,47 \pm 0,08 \mathrm{~b}$ & 0,00 & 100,00 \\
\hline
\end{tabular}

${ }^{1}$ Análise estatística e Teste de Tukey $(p=0,0113)$.

Tabela 04 - Média \pm erro padrão do valor de sólidos totais (\%) de leite in natura comercializado informalmente nos municípios de Cerqueira César, Manduri e Avaré no estado de São Paulo. Análise estatística complementada com o teste de Tukey $(p<0,05)$.

\begin{tabular}{cc}
\hline Cidades & Média \pm erro padrão \\
\hline Cerqueira César & $11,38 \pm 0,10 \mathrm{a}^{1}$ \\
Manduri & $11,68 \pm 0,14 \mathrm{a}$ \\
Avaré & $13,20 \pm 0,26 \mathrm{~b}$ \\
${ }^{1}$ Análise estatística e Teste de Tukey $(p<0,0001)$.
\end{tabular}


Tabela 05 - Média \pm erro padrão e porcentagem de sólidos não gordurosos (\%) de leite in natura comercializado informalmente nos municípios de Cerqueira César, Manduri e Avaré no estado de São Paulo. Análise estatística complementada com o teste de Tukey $(p<0,05)$.

\begin{tabular}{cccc}
\hline \multirow{2}{*}{ Cidade } & Média \pm erro & \multicolumn{3}{c}{$\%$} \\
\cline { 3 - 4 } & padrão & $\mathbf{< 8 , 4 \%}$ & $\mathbf{2 8 , 4 \%}$ \\
\hline Cerqueira César & $8,20 \pm 0,09 \mathrm{a}^{1}$ & 86,67 & 13,33 \\
Manduri & $8,42 \pm 0,13 \mathrm{a}$ & 53,33 & 46,67 \\
Avaré & $9,73 \pm 0,20 \mathrm{~b}$ & 0,00 & 100,00 \\
\hline
\end{tabular}

${ }^{1}$ Análise estatística e Teste de Tukey $(p<0,0001)$.

Tabela 06 - Média \pm erro padrão e porcentagem do índice crioscópico $\left({ }^{\circ} \mathrm{H}\right)$ de leite in natura comercializado informalmente nos municípios de Cerqueira César, Manduri e Avaré no estado de São Paulo. Análise estatística complementada com o teste de Tukey $(p<0,05)$.

\begin{tabular}{|c|c|c|c|c|}
\hline \multirow[b]{2}{*}{ Cidade } & \multirow[b]{2}{*}{$\begin{array}{c}\text { Média } \pm \\
\text { erro padrão }\end{array}$} & \multicolumn{3}{|c|}{${ }^{\mathbf{0}} \mathbf{H}$} \\
\hline & & $>-0,530$ & $\begin{array}{c}-0,530-- \\
0,550\end{array}$ & $<-0,550$ \\
\hline $\begin{array}{l}\text { Cerqueira } \\
\text { César }\end{array}$ & $\begin{array}{l}-0,537 \pm \\
0,007 a^{1}\end{array}$ & 20,00 & 46,67 & 33,33 \\
\hline Manduri & $\begin{array}{c}-0,545 \pm \\
0,008 \mathrm{a}\end{array}$ & 26,67 & 53,33 & 20,00 \\
\hline Avaré & $\begin{array}{r}-0,646 \pm \\
0,035 \mathrm{~b}\end{array}$ & 6,67 & 20,00 & 73,33 \\
\hline
\end{tabular}

${ }^{1}$ Análise estatística e Teste de Tukey $(p=0,0008)$. 
Tabela 07 - Porcentagem (\%) de análise qualitativa de enzimas (peroxidase e fosfatase), de substância orgânica (formaldeído) e de substâncias inorgânicas $\left(\mathrm{H}_{2} \mathrm{O}_{2}, \mathrm{ClO}^{-} \mathrm{e} \mathrm{Cl}^{-}\right)$presentes em leite in natura comercializado informalmente nos municípios de Cerqueira César, Manduri e Avaré no estado de São Paulo. Análise estatística complementada com o teste de Tukey $(p<0,05)$.

\begin{tabular}{cccc}
\hline \multirow{2}{*}{ Análise } & Cidade & \multicolumn{3}{c}{$\%$} \\
\cline { 3 - 4 } Fosfatase & Ausente & Presente \\
& Cerqueira César & 26,67 & 73,33 \\
& Manduri & 13,33 & 86,67 \\
& Avaré & 0,00 & 100,00 \\
\hline \multirow{2}{*}{ Formol } & Cerqueira César & 100,00 & 0,00 \\
& Manduri & 100,00 & 0,00 \\
& Avaré & 100,00 & 0,00 \\
\hline \multirow{2}{*}{$\mathrm{H}_{2} \mathrm{O}_{2}$} & Cerqueira César & 100,00 & 0,00 \\
& Manduri & 100,00 & 0,00 \\
& Avaré & 100,00 & 0,00 \\
$\mathrm{ClO}^{-}$ & Cerqueira César & 100,00 & 0,00 \\
& Manduri & 100,00 & 0,00 \\
& Avaré & 100,00 & 0,00 \\
\hline \multirow{2}{*}{$\mathrm{Cl}^{-}$} & Cerqueira César & 100,00 & 0,00 \\
& Manduri & 100,00 & 0,00 \\
& Avaré & 100,00 & 0,00 \\
\hline \multirow{2}{*}{ Peroxidase } & Cerqueira César & 0,00 & 100,00 \\
& Manduri & 13,33 & 86,67 \\
& Avaré & 0,00 & 100,00 \\
\hline
\end{tabular}

\section{Discussão}

As amostras do experimento apresentaram resultados negativos para a presença de cloretos, hipoclorito, água oxigenada e formol, substâncias que são frequentemente adicionadas para mascarar a presença de microorganismos decorrentes de contaminação. (BEHMER, 1984)

As amostras com acidez elevadas no experimento podem estar associadas ao aumento da concentração de ácido lático no leite, formado pela fermentação da lactose por bactérias mesófilas, podendo indicar elevada contaminação microbiológica devido a falta de higiene na obtenção e 
conservação do produto (BRASIL, 2002). Componentes como citratos, fosfatos e proteínas também podem interferir na acidez do leite (SANTOS, 2004).

Fontaneli (2001) relatou que os fatores como raça, polimorfismo das proteínas, produção de leite, estágio da lactação, momento da ordenha, intervalo da ordenha, nutrição, sanidade, estresse calórico e diluição do leite podem interferir na acidez do leite. Zafalon \& Nader Filho (2005) mostraram que animais com os quartos mamários infectados com mastite subclínica apresentaram valores diminuídos de acidez titulável.

Com base nessas informações, o presente trabalho também apresentou valores abaixo do parâmetro recomendado por Brasil (2002) e esses valores podem estar associados ao processo infeccioso ou à diluição do leite.

As porcentagens alteradas de gordura, extrato seco desengordurado e sólidos totais nas amostras podem estar relacionadas a dois fatores principais: (a) a variação individual dos animais, influída por variáveis como a alimentação, idade, período de lactação e raça; e (b) a adição de substâncias visando fraudes volumétricas, como água. A variação individual altera de maneira menos significativa os valores de gordura e pouco influencia os outros parâmetros avaliados. A fraude por adição de substâncias que visam aumentar o volume pode ser detectada quando são confrontados resultados das análises de densidade e a crioscopia. A variação entre as diversas amostras ressaltam a importância da padronização para adequação do produto à legislação (BRASIL, 2002).

Paula et al. (2010) relataram que a densidade global do leite varia inversamente com o conteúdo de gordura. O aumento da densidade se dá pela redução da gordura, que entre os elementos principais do leite é o de menor densidade. Portanto, o desnatamento parcial do leite ou o acréscimo de leite desnatado aumenta a densidade do leite. A densidade abaixo do nível pode indicar fraude no leite por adição de água, problemas nutricionais ou ainda problemas na saúde do animal (PAULA, CARDOSO \& RANGEL, 2010). Como as amostras não sofreram nenhum processamento industrial, a hipótese de desnate na alteração da densidade é pouco provável. 
A determinação do índice crioscópico do leite é considerada uma prova de precisão, onde os valores apresentam baixa variabilidade. Sendo utilizado na inspeção com o objetivo de identificar fraudes por adição de água. A diminuição do índice crioscópico pode estar relacionada ao congelamento do leite, aumento da concentração de solutos e aumento da acidez. A adição de água ou características do rebanho podem levar a um aumento desse índice (BORGES \& PINTO, 2007).

Pode-se associar de maneira geral no presente trabalho os casos de baixos índices crioscópicos com o aumento da acidez titulável. Para as amostras com índices superiores a $-0,530^{\circ} \mathrm{H}$ suspeita-se da adição de água (BRASIL, 2002).

A destruição da fosfatase alcalina ocorre em temperatura semelhante à de inativação dos patógenos, portanto sua ausência indica a salubridade do leite. Também a sua pesquisa é utilizada para avaliar a eficiência do processo de pasteurização. A peroxidase é mais resistente ao calor quando comparada com a fosfatase alcalina, também sendo utilizada para controlar a pasteurização, sendo que quando presente indica que não houve o superaquecimento do leite durante o processo (ORDÓNEZ, 2005).

Os resultados indicaram que algumas amostras de Cerqueira Cezar e Manduri podem ter sido fervidas ou aquecidas.

\section{Conclusão}

Com base nessas informações, concluímos que:

(a) A qualidade físico-química de leite in natura não inspecionado e comercializado por inúmeros comerciantes ambulantes das cidades de Cerqueira César, Manduri e Avaré no estado de São Paulo não é satisfatória e legal.

(b) Os consumidores devem se conscientizar em consumir leite inspecionado pelo governo federal e/ou pelo governo estadual por apresentar um controle físico-químico do produto. 
DALAQUA, S. et al. Avaliação físico-química de leite in natura comercializado informalmente nas cidades de Cerqueira César, Manduri e Avaré/SP. PUBVET, Londrina, V. 6, N. 33, Ed. 220, Art. 1464, 2012.

\section{Agradecimentos}

O Laboratório de Química e Bioquímica das Faculdades Integradas Regionais de Avaré, Fundação Regional Educacional de Avaré, São Paulo e o Laboratório Físico-Química da Disciplina de Inspeção de Alimentos de Origem Animal, Departamento de Higiene Veterinária e Saúde Pública, Faculdade de Medicina Veterinária e Zootecnia, Universidade Estadual Paulista "Júlio de Mesquita Filho" (UNESP), Campus de Botucatu, São Paulo, Brasil.

\section{Referências}

BEHMER, M. L. A. Tecnologia do leite: leite, queijo, manteiga, caseína, iogurte, sorvetes e instalações: produção, industrialização, analise. 130ed. São Paulo: Nobel, 1984.

BRASIL. Ministério da Agricultura, Pecuária e abastecimento. Instrução Normativa no 51 , de 18 de setembro de 2002. Regulamento Técnico de Identidade e Qualidade de Leite. Brasília, DF. 2002.

BRASIL. Ministério da Agricultura, Pecuária e abastecimento. Artigo 475, Regulamento da Inspeção Industrial e Sanitária de Produtos de Origem Animal (RIISPOA). Brasília, DF. 1998.

BRASIL. Ministério da Agricultura, Pecuária e abastecimento. Artigo 550, Regulamento da Inspeção Industrial e Sanitária de Produtos de Origem Animal (RIISPOA). Brasília, DF. 1998

BRASIL. Empresa Brasileira de Pesquisa Agropecuária. Embrapa. Gado de Leite. Brasília. 2012.

Disponivel

em: Http://sistemasdeproducao.cnptia.embrapa.br/FontesHTML/Leite/LeiteSudeste/importancia.ht $\mathrm{ml}$. Acesso: 28 março 2012.

BORGES, K.A.; PINTO, A.T. Variações no índice crioscópico de amostras de leite recebidas na plataforma de um laticínio, no período de janeiro a agosto de 2007. Porto Alegre. RS, 2007.

BRITO, M.A.V.P., ARCURI, E.F., BRITO, J.R.F. Testando a qualidade do leite. In: DURÃES, M.C.; MARTINS, C.E.; DERESZ, F.; BRITO, J.R.F.; FREITAS, A.F.; PORTUGAL, J.A.B.; COSTA, C.N. MINAS LEITE. 2., 2000, Juiz de Fora. Avanços tecnológicos para o aumento da produtividade leiteira. Anais... Juiz de Fora: Embrapa Gado de Leite, 2000. p.64.

CASTANHEIRA, A. C. Manual Básico Controle de Qualidade de Leite e Derivados. Cap-Lab. São Paulo, 2010.

FONSECA, L. M., RODRIGUES, R., SOUZA, M. R. Índice crioscópico do leite. Cadernos Técnicos da Escola de Veterinária da UFMG, n.13, p.73-84, 1995.

FONTANELI, R. S. Fatores que afetam a composição e as características físico-químicas do leite, Rio Grande do Sul, 2001.

OLIVAL, A. A.; SPEXOTO, A. A. Leite informal no Brasil: aspectos sanitários e educativos. Higiene Alimentar, São Paulo, v. 18, n. 119, p. 12-17, 2004. 
ORDÓNEZ, J. A.; Tecnologia de alimentos: alimentos de Origem animal. São Paulo: Artmed. Vol.2, 2005.

PAULA, F. P.; CARDOSO, C. E.; RANGEL, M. A. C. Análise Físico-química do Leite Cru Refrigerado Proveniente das Propriedades Leiteiras da Região Sul Fluminense. Revista Eletrônica TECCEN, Vassouras, v. 3, n. 4, p. 7-18, out./dez., 2010.

PEREDA, J. A. Tecnologia de Alimentos vol.2 Componentes dos Alimentos e Processos. Artmed. 2005. 13 p.

QUEIROZ, J. C. Avaliação sanitária do leite cru distribuído nos Municípios de Juquitiba e Itapecerica da Serra, São Paulo, 1990-1992, 1995. [Tese de Doutorado - Faculdade de Saúde Pública da USP].

SANTOS, M. V. Aspectos não microbiológicos afetando a qualidade do leite. In: J. W. Durr: M. P. Carvalho: M. V. Santos (Org.). O Compromisso com a qualidade do leite no Brasil. Passo Fundo, 2004, p.2.

TIMM, C. D.; GONZALEZ, H. L.; OLIVEIRA, D. S.; BÜCHLE , J.; ALEXIS, M. A.;COELHO , F. J. O.; PORTO C. Avaliação da qualidade microbiológica do leite pasteurizado integral produzido em microusinas da região sul do Rio Grande do Sul. Revista Higiene Alimentar, São Paulo, v. 17, n. 106, p. 100-104, 2003.

TRONCO, V.M. Manual para Inspeção da Qualidade do Leite. $2^{\mathrm{a}}$ ed. Santa Maria: UFSM, 2003. $192 p$.

ZAFALON, L. F.; NADER FILHO, A.; AMARAL, L.A.; OLIVEIRA, J.V.; F.; RESENDE, F. D. Alterações da composição e da produção de leite oriundo de quartos mamários de vacas com e sem mastite subclínica de acordo com o estágio e o número de lactações. Arq. Inst. Biol., São Paulo, v.72, n.4, p.419-426, out./dez., 2005. 